\title{
Micobacteriose por Mycobacterium marinum em "linguado" Paralichthys orbignyanus e em "barber goby" Elacatinus figaro: diagnóstico histopatológico e imuno-histoquímico ${ }^{1}$
}

\author{
Luis A. Romano ${ }^{2 *}$, Luís A. Sampaio ${ }^{3}$ e Marcelo B. Tesser ${ }^{3}$
}

\begin{abstract}
Romano L.A., Sampaio L.A. \& Tesser M.B. 2012. [Micobacteriosis by Mycobacterium marinum in Brazilian flounder Paralichthys orbignyanus and barber goby Elacatinus figaro: Histopathological and imunohistochemical diagnosis.] Micobacteriose por Mycobacterium marinum em linguado Paralichthys orbignyanus e em "barber goby" Elacatinus figaro: diagnóstico histopatológico e imuno-histoquímico. Pesquisa Veterinária Brasileira 32(3):254-258. Laboratório de Imunologia Patologia de Organismos Aquáticos, Instituto de Oceanografia, Universidade Federal do Rio Grande, Av. Itália Km 8, Bairro Carreiros, Rio Grande, RS 96201-900, Brazil. E-mail: dcluis@yahoo.com

Mycobacteriosis affects various species of fish, including those cultured with commercial purposes. It is a chronic systemic with granuloma forming disease known as fish mycobacteriosis. In the last few years the interest of fish culture has been increasing due to the reduction of the natural fish stocks. However the intensification of fish culture has collaborated to the development of diseases such as mycobacteriosis, causing losses due to the chronic characteristics and difficult diagnosis. This study is to report two cases of mycobacteriosis observed at "Laboratório de Piscicultura Estuarina e Marinha of the Universidade Federal do Rio Grande (FURG)", one for Brazilian flounder Paralichthys orbignyanus and another for barber goby Elacatinus figaro. The Fite-Faraco staining protocol was used. Membranes of mycobacterial cells contain a waxy substance composed of mycolic acids. These are ß-hydroxy carboxylic acids with chain lengths of up to 90 carbon atoms. The property of acid fastness is related to the carbon chain length of the mycolic acid found in any particular species. The fish mycobacterium is much less acid and alcohol fast than the tubercle bacillus and the classic Ziehl-Neelsen Staining Protocol may give false results. The presence of mycobacterial antigen lesions was studied by immunohistological methods using monoclonal antibodies to Mycobacterium marinum. Humans may be infected by these bacteria and develop cutaneous granuloma. In this paper the necessity is stressed for a correct diagnosis of the disease, contributing to the prevention of its establishment in aquatic facilities, and thus, preserving cultured fish as well as human beings from infection.
\end{abstract}

INDEX TERMS: Mycobacterium marinum, mycobacteriosis, Paralichthys orbignyanus, Elacatinus figaro, inmunohistochemistry.

RESUMO.- As micobacterioses afetam várias espécies de peixes, tanto comerciais como ornamentais. É uma enfermidade sistêmica com formação de granulomas, conheci-

\footnotetext{
${ }^{1}$ Recebido em 9 de dezembro de 2011.

Aceito para publicação em 23 de janeiro de 2012.

${ }^{2}$ Laboratório de Imunologia Patologia de Organismos Aquáticos, Instituto de Oceanografia, Universidade Federal do Rio Grande (FURG), Av. Itália Km 8, Bairro Carreiros, Rio Grande, RS 96201-900, Brasil. *Autor para correspondência: dcluis@yahoo.com

${ }^{3}$ Laboratório de Piscicultura Estuarina e Marinha, Instituto de Oceanografia, FURG, Rio Grande, RS.
}

da como micobacteriose de peixes. 0 desenvolvimento da aquicultura tem aumentado o número de casos com essa enfermidade que muitas vezes é de difícil diagnóstico. Neste trabalho apresentamos dois casos de micobacterioses em Paralichthys orbignyanus e Elacatinus figaro provenientes do Laboratório de Piscicultura Estuarina e Marinha da Universidade Federal do Rio Grande (FURG). As micobactérias de peixes possuem menos ácidos graxos que as de mamíferos, por isso foi utilizado o protocolo de coloração de Fite-Faraco, uma vez que o protocolo de coloração clássico de Ziehl Neelsen pode resultar em falsos negativos. Para determinar o 
tipo de micobactéria foi utilizada a imuno-histoquímica com a qual se pode diagnosticar a presença de Mycobacterium marinum. A enfermidade pode ser transmitida para o homem e com esse trabalho ressalta-se a necessidade de fazer o diagnóstico correto e implantar medidas de proteção para as pessoas que estão em contato com os peixes infectados.

TERMOS DE INDEXAÇÃO: Mycobacterium marinum, micobacteriose, Paralichthys orbignyanus, Elacatinus figaro, imuno-histoquímica.

\section{INTRODUÇÃO}

As bactérias representam os agentes biológicos que mais frequentemente produzem enfermidades em peixes, podendo ocasionar mortalidades elevadas tanto em peixes silvestres ou em cativeiro (Stoskopf 1993). A micobacteriose em peixes é uma doença sistêmica, granulomatosa, produzida por bacilos Gram positivos, ácido-álcool resistente que medem entre resistentes ao álcool e que medem entre 1 e $4 \mu \mathrm{m}$ de comprimento (Decostere et al. 2004). As doenças causadas por micobacterioses estão entre as mais comuns em peixes em todo mundo (Noga et al. 1990). Sua severidade pode ser crônica e associada com baixa mortalidade, até casos mais agudos onde todo o lote de peixes é perdido (Kent et al. 2004).

A transmissão horizontal é pouco frequente. No entanto, foi comprovado experimentalmente a sua transmissão por ingestão de alimentos contaminados por micobactérias (Romano 1990, Ishikawa 2001). Recentemente, evidências apontam que o modo de infestação por micobactérias seja principalmente pelo intestino, como foi visto em Danio rerio (Harrif et al. 2007). Geralmente, os casos iniciam-se de maneira crônica. Os peixes apresentam letargia e deixam de se alimentar, podem apresentar ulcerações na pele e alterações de pigmentação, exoftalmia uni ou bilateral (Decostere et al. 2004). Granulomas de coloração branco-acinzentada podem estar presentes em qualquer região do parênquima, mas com maior predominância no baço, fígado e rim.

Desde a primeira descrição em Cyprinus carpio no ano de 1894, a enfermidade foi registrada em aproximadamente 40 famílias e 151 espécies de peixes em todo mundo, tanto em água doce como marinha (Romano 1985, Sahar et al. 2001). Ainda, as micobacterioses de peixes possuem ação zoonótica, causando feridas nas mãos dos que manipulam peixes enfermos (Lewis et al., 2003). Essa enfermidade em humanos é de difícil diagnóstico e terapia, estando incluída dentro das micobacterioses atípicas (Ryan \& Bryant, 1997).

Os sinais clínicos desta doença em peixes sugerem apenas suspeita, o diagnóstico definitivo é feito por, isolamento bacteriano ou cortes histológicos. De acordo com Pourahmad et al. (2009) a histologia é um método pouco sensível ou específico. No entanto, a realização de técnicas especificas para bacilos ácido-álcool resistentes podem reduzir o número de casos falsos negativos. Além disso, a técnica clássica (Ziehl-Neelsen) para micobacteriose pode resultar em grande quantidade de falsos negativos devido a baixa quantidade de ácido micolítico. Deste modo, propomos nesse trabalho a técnica de Fite-Faraco como uma técnica de maior especificidade, pois a mesma não utiliza solventes orgânicos. A caracterização taxonômica desse bacilo pode ser realizada por meio molecular, que são complexas e custosas. Como alternativa e demonstrado nesse trabalho, a utilização de anticorpo monoclonal pode caracterizar taxologicamente esse bacilo.

Os casos de micobacterioses relatados nesse artigo foram de duas espécies estudadas no Laboratório de Piscicultura Estuarina e Marinha da FURG, o linguado Paralichthys orbignyanus e outro no "barber goby" Elacatinus figaro, ambas as espécies com interesse comercial (Sampaio et al. 2008, Shei et al. 2010).

\section{MATERIAL E MÉTODOS}

Foram estudados dois exemplares de Elacatinus figaro e um exemplar de Paralichthys orbignyanus provenientes do Laboratório de Piscicultura Estuarina e Marinha. Os animais foram anestesiados com benzocaína (150ppm) e sacrificados em gelo. Em seguida, os peixes foram necropsiados de acordo com a metodologia proposta por Romano (1987). Os exemplares de E. figaro foram fixados inteiros devido ao seu pequeno tamanho com apenas uma abertura em todo o abdômen. 0 baço, o rim e o fígado, bem como os peixes foram fixados em formol $10 \%$ tamponado. Todas as amostras foram processadas em equipamento automático (LUPE PT05) e a inclusão feita em paraplast. Os blocos foram cortados em micrótomo (LUPE MRP03) a uma espessura de $3 \mu \mathrm{m}$ e corados com hematoxilina e eosina e Fite- Farazo segundo o seguinte protocolo: As secções foram desparafinadas em solução composta por duas partes de xilol e uma parte de óleo de amendoim durante 15 minutos. Em seguida as secções foram lavadas em água corrente para retirar a mistura de xilol/óleo remanescentes. A diferenciação foi realizada por meio de ácido sulfúrico $10 \%$ durante 2 minutos. Novamente uma lavagem em água corrente foi realizada e em seguida em água destilada. Posteriormente, as secções foram secas e não foram desidratas em álcool. Foi utilizado o xilol e em seguida a lâmina montada com Bálsamo do Canadá (Fite et al. 1947).

A imunohistoquímica foi realizada com anticorpo monoclonal anti-Mycobacterium marinum (Microtek International-Buenos Aires Argentina). As lâminas histológicas foram incubadas por 20 minutos em $0,3 \% \mathrm{H}_{2} \mathrm{O}_{2}$ em tampão Tris. Posteriormente elas foram incubadas em soro suíno diluído 1:5 em tampão fosfato (PBS) por 30 minutos e novamente incubadas com o anticorpo monoclonal anti-Mycobacterium marinum em uma diluição de 1:600. Foi utilizado um complexo peroxidase-antiperoxidase (PAP-Dako) diluído em PBS por minutos. Como cromógeno foi utilizado a diaminobenzidina com $\mathrm{H}_{2} \mathrm{O}_{2}$ a $0,03 \%$ e como corante de contrates o verde luz.

\section{RESULTADOS E DISCUSSÃO}

Clinicamente, os exemplares de Elacatinus figaro apresentaram distensão abdominal proeminente com acumulação de líquido ascítico. No caso de Paralichthys orbignyanus o exemplar estudado apresentou hiperpigmentação cutânea e exoftalmia unilateral com hemorragia intraocular (Fig.1). 0 fígado estava friável e foi observada rinomegalia com granulações milimétricas sobre a superfície dos rins (Fig.2).

Histologicamente o baço, fígado e o rim de ambas as espécies apresentaram granulomas constituídos por um centro necrótico tipo caseoso rodeado por células epitelióides e linfócitos (Fig.3 e 4). A morfologia dessas lesões sugeria uma micobacteriose, desta forma foi realizada a técnica de 


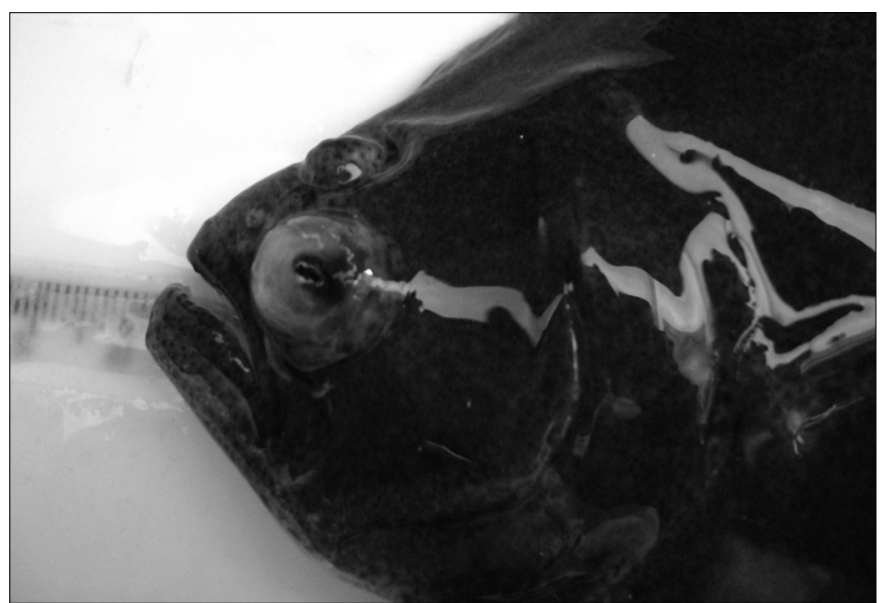

Fig.1. Paralichthys orbignyanus com exoftalmia e hemorragia ocular.

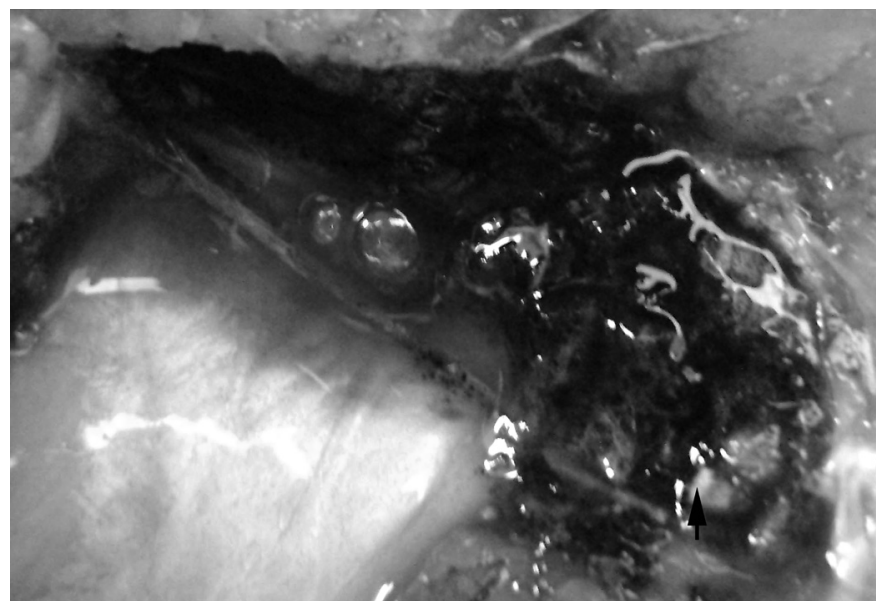

Fig.2. Paralichthys orbignyanus com nódulos esbranquiçados milimétricos no parênquima renal (seta).

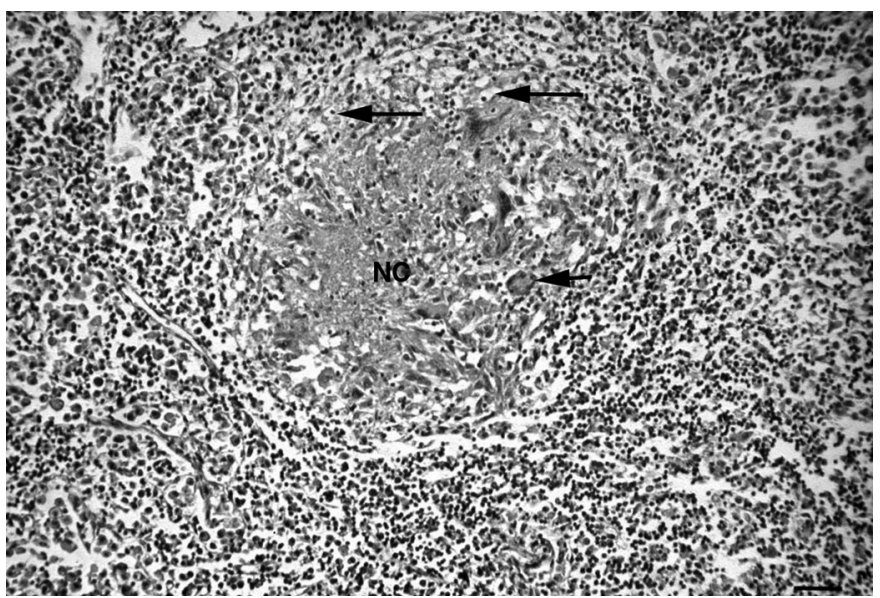

Fig.3. Parênquima esplénico de Elacatinus figaro com lesão granulomatosa e necrose central de tipo caseoso (NC) rodeado de células gigantes multinucleadas (flecha curta) e células epitelióides e linfócitos (seta longa). HE, barra $=50 \mu \mathrm{m}$ )

Fite-Faraco para bactéria ácido-alcoólica resistente. Foram encontrados numerosos bacilos de 2-6 $\mu \mathrm{m}$ de comprimento, principalmente no baço, fígado e rins (Fig.5). No caso de $P$. Orbignyanus, foram encontrados granulomas no te-

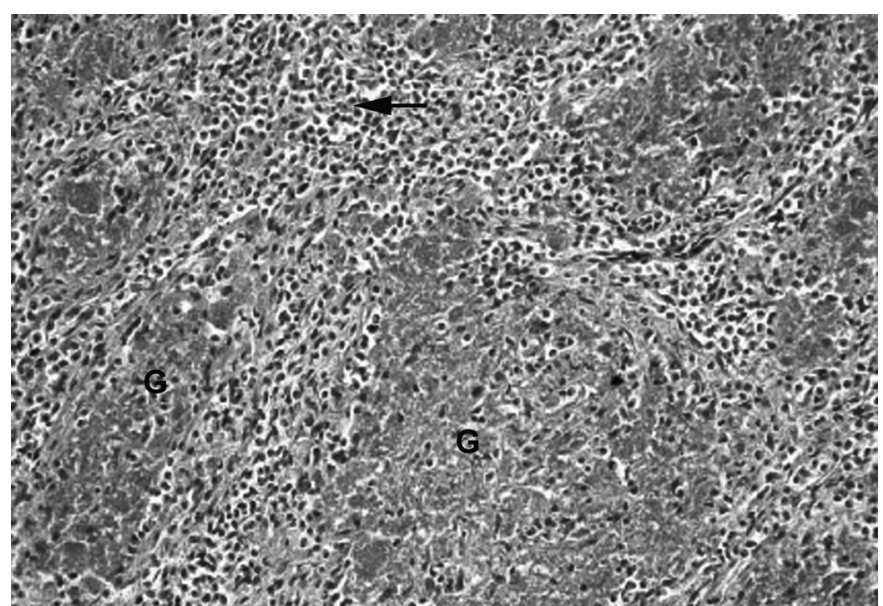

Fig.4. Pronefros de Paralichthys orbignyanus com células linfo hematopoiéticas (seta) e várias lesões granulomatosas (G). HE, barra $=50 \mu \mathrm{m}$.

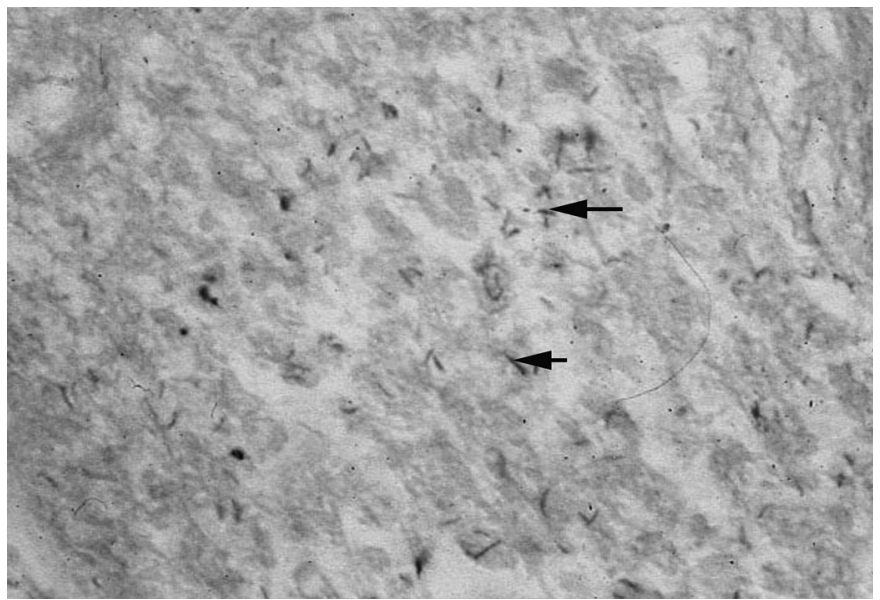

Fig.5. Granuloma no baço observado na Figura 3 com abundantes bacilos ácido-álcool resistentes que correspondem a micobactérias (setas). Fite-Faraco, barra $=10 \mu \mathrm{m}$.

cido adiposo retro-ocular e hemorragia no humor vítreo com inúmeras micobactérias (Fig.6). As características da coloração desses bacilos diferem das observadas em micobactérias de mamíferos e humanos. Com a técnica de Ziehl-Neelsen os bacilos dos peixes não se tingem de vermelho de forma intensa. No entanto, com a técnica de Fite-Faraco, tanto as micobactérias humanas como as não humanas são marcadas intensamente de vermelho, devido a afinidade que a coloração de Ziehl-Neelsen possui com os lipídios e com as bactérias com uma típica estrutura lipídica de sua parede celular que atua como uma barreira permeável unicamente para solutos hidrofílicos. Os compostos hidrofílicos atravessam lentamente a parede celular devido a pouca fluidez dos ácidos micólicos e a espessura total da parede bacteriana (Campbell \& Naworal 1969, Tønjum 1998, Sacco et al. 2007). As micobactérias que afetam os peixes apresentam menor quantidade de ácidos graxos, que durante a retirada da parafina do tecido com um solvente orgânico, como o xilol, os ácidos graxos se dissolvem e a coloração pode resultar em falso-negativo. Com a técnica de Fite-Faraco modificada, no momento da retirada da parafina se 
utiliza uma mistura de óleo de amendoim e xilol preservando mais de $60 \%$ dos ácidos graxos, principalmente os ácidos ß-hidróxi- carboxil com comprimento de cadeia maior de 90 átomos de carbono que são os que apresentam maior afinidade pelo corante (Fite et al. 1947).

A classificação do gênero Mycobacteriun não é clara. Originalmente a micobactéria foi denominada de $\mathrm{Myco}$ bacteriun piscium. No manual de bacteriologia de Bergey (1974) a espécie patogênica mais comum é M. marinum, que substitui a antiga denominação de M. pisciun, M. anabrante e M. salmoniphilun (Reichenbach-Klinke 1982). A imuno-histoquímica demonstrou que se trata de uma infecção sistêmica causada por M. marinum para ambas as espécies (Fig.7).

A imuno-histoquímica é de muita utilidade para o diagnóstico de diversas patologias animais e humanas; pois permite detectar antígenos de diferentes agentes patológicos somente fixando os tecidos com formol tamponado.

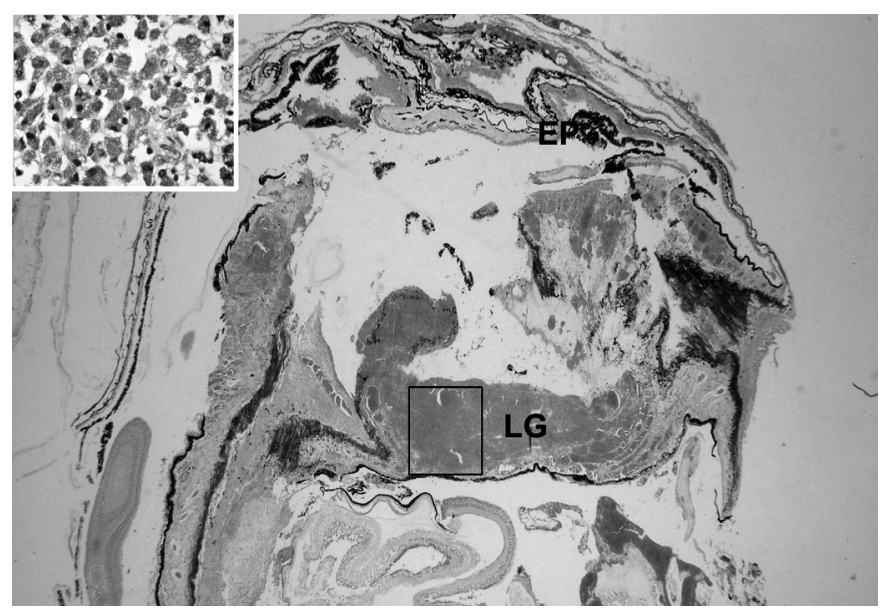

Fig.6. Globo ocular de Paralichthys orbignyanus onde se observa lesões granulomatosas por debaixo da coroide (retângulo marcado LG), se pode observar o epitélio pigmentário ocular (EP). No detalhe na parte superior esquerda da figura se pode observar um detalhe das micobactérias encontradas nos granulomas. Fite-Faraco, barra $=100 \mu \mathrm{m}$. No detalhe Fite-Faraco, barra $=10 \mu \mathrm{m})$.

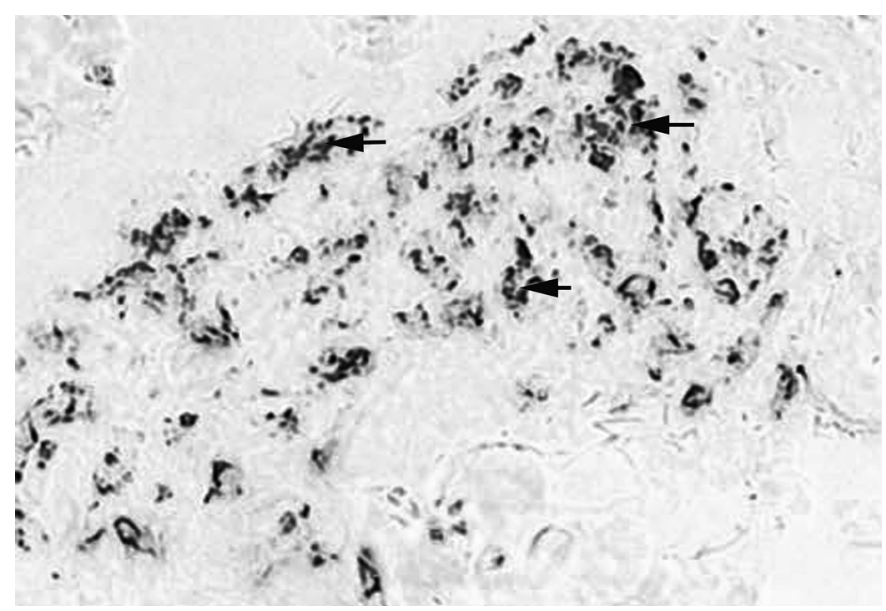

Fig.7. Imuno-histoquímica do granuloma renal onde se observa micobácterias correspondentes a Mycobacterium marinum (setas). Anti-M.marinum, barra $=10 \mu \mathrm{m}$.
Esta técnica é eficiente para o diagnóstico de bactérias de difícil isolamento e cultivo como são as micobactérias (Gómez et al. 1993).

Conclui-se que técnica de Fite-Faraco demonstrou ser sensível para detecção de microbactérias em geral e de maior sensibilidade para microbactéria de peixes do que a técnica clássica. Por último a utilização de anticorpo monoclonal para a caracterização sistemática do bacilo foi altamente especifico podendo servir de alternativa para a técnicas moleculares que são de maior complexidade e custo.

\section{REFERÊNCIAS}

Bergery D.H., Buchanan R.E \& Gibbons N.E. 1974. Manual of Determinative Bacteriology. Williams and Wilkins Co., Baltimore. 548p.

Campbell I.M., \& Naworal J. 1969. Composition of the saturated and monounsaturated fatty acids of Mycobacterium phlei. J. Lipid Res. 10:593598.

Decostere A., Hermans K. \& Haesebrouck F. 2004. Piscine mycobacteriosis: A literature review covering the agent and the disease it causes in fish and humans. Vet. Microbiol. 99:59-166.

Fite G.L., Cambre F.J. \& Turner M.H. 1947. Procedures for demonstrating lepra bacilli in paraffin sections. Archs Pathol. 43:624-625.

Gómez S., Bernabé A., Gómez M.A., Navarro J.A. \& Sánchez J. 1993. Fish mycobacteriosis: morphopathological and immunocytochemical aspects. J. Fish Dis. 16:137-141.

Harriff M.J., Bermudez L.E. \& Kent M.J. 2007. Experimental exposure of zebrafish, Danio rerio (Hamilton), to Mycobacterium marinum and Mycobacterium peregrinum reveals the gastrointestinal tract as the primary route of infection: A potential model for environmental mycobacterial infection. J. Fish Dis. 30:587-600.

Ishikawa C.M., Matushima E.R., Oliveira de Souza C.W., Timenetsky J. \& Ranzani-Paiva M.T. 2001. Micobacteriose em peixes. Bolm Instituto de Pesca 27:231-242.

Kent M.L., Whipps C.M., Matthews J.L., Florio D., Watral V., Bishop-Stewart J.K., Poort M. \& Bermudez L. 2004. Mycobacteriosis in zebrafish (Danio rerio) research facilities. Comp. Biochem. Physiol. C, Toxicol. Pharmacol. 138:383-390.

Lewis F.M.T., Marsh B.J. \& Von Reyn C.F. 2003. Fish tank exposure and cutaneous infection due to Mycobacterium marinum: tuberculin skin testing, treatment, and prevention. Clin. Infect. Dis. 37:390-397.

Noga E.J., Wright J.F. \& Pasarell L. 1990. Some unusual features of mycobacteriosis in the cichlid fish Oreochromis mossambicus. J. Comp. Pathol. 102:335-344.

Pourahmad F., Thompson K.D., Adams A. \& Richards R.H. 2009. Detection and identification of aquatic mycobacteria in formalin-fixed, paraffin-embedded fish tissues. J. Fish Dis. 32:409-419

Reichenbach-Klinke H.H. 1982. Enfermedades de los Peces. Editorial Acribia, Zaragoza. 507p.

Romano L.A. 1985. Micobacteriosis de los peces. Documental Vet. 8:11.

Romano L.A. 1987. Estudio Histopatológico de los peces. Documental Vet. 12:8-7.

Romano L.A. 1990. Ictiopatología (Artículo Especial). Ecognicion 5:32-35.

Ryan J.M. \& Bryant G.R. 1997. Fish tank granuloma: A frequently misdiagnosed infection of the upper limb. J. Accident Emerg. Med. 14:398-399.

Ruiz S.M., Medina Castillo D., Vences M.Y. \& Vidal A.F. 2002. Granuloma de las piscinas de distribución esporotricoide. Revta Cent. Dermatol. Pascua 11:150-152.

Sacco E., Suarez Covarrubias A., O’Hare E.M., Carroll P., Eynard N.T., Jones A., Parish T., Dafne M., Backbro K. \& Que'Mard A. 2007. The missing piece of the type II fatty acid synthase system from Mycobacterium tuberculosis. Proc. Natl Acad. Sci. 104:14628-14633.

Sahar H., El-Etr L.Y. \& Cirillo J.D. 2001. Fish Monocytes as a Model for Mycobacterial Host-Pathogen Interactions. Infect. Immun. 69:7310-7317. 
Sampaio L.A., Robaldo R.B. \& Bianchini,A. 2008. Hormone induced ovulation, natural spawning and larviculture of Brazilian flounder Paralichthys orbignyanus (Valenciennes, 1839). Aquacult. Res. 39:712-717.

Shei M., Miranda-Filho K.M., Rodrigues R.V. \& Sampaio L.A. 2010. Production of juvenile barber goby Elacatinus figaro in captivity: Developing technology to reduce fishing pressure on an endangered species. Marine Biodiversity Records 3:57.

Stoskopf M.K. 1993. Fish Medicine. W.B. Saunders Company, Philadelphia. 888p.

Tønjum T., Welty D.B., Jantzen E. \& Small P.L. 1998. Differentiation of Myco- bacterium ulcerans, M. marinum, and M. haemophilum: Mapping of their relationships to $M$. tuberculosis by fatty acid profile analysis, DNA-DNA Hybridization, and 16S rRNA Gene Sequence Análisis. J. Clin Microbiol. 36:918-925.

Williams C.S. \& Riordan D.C. 1973. Mycobacterium marinum (Atypical Acid-Fast Bacillus) infections of the hand: A report of six cases. J. Bone Joint Surg. Am. 55:1042-1050.

Zanoni R.G., Florio D., Fioravanti M.L., Rossi M. \& Prearo M. 2008. Occurrence of Mycobacterium spp. in ornamental fish in Italy. J. Fish Dis. 31:433-44. 